\title{
Ischemic Stroke Subtype Classification: An Asian Viewpoint
}

\author{
Bum Joon Kim, Jong S. Kim \\ Department of Neurology, Asan Medical Center, Seoul, Korea
}

Proper classification of the causative mechanism of stroke is important for optimizing stroke treatment and assessing prognosis. The primary etiology of stroke differs according to race and ethnicity: emboli originating from the heart or extracranial large arteries are common in Western populations, whereas small-vessel occlusion or intracranial atherosclerosis is more prevalent in Asians. Intracranial atherosclerosis frequently leads to stroke by branch-artery occlusion, and the degree of stenosis in these cases is often $<50 \%$. Mild intracranial atherosclerotic stenosis may cause distal embolization, if the atherosclerotic plaque is sufficiently vulnerable. Moreover, high-resolution magnetic resonance imaging studies have identified small plaques causing infarction, even in patients with normal-appearing vascular findings. Such cases, which are prevalent in Asia, could not be classified as large-artery atherosclerosis by previous classification systems. Additionally, single subcortical infarctions, which are usually attributed to lipohyalinotic small-vessel disease, can have other causes, including microatheroma of perforators and atherothrombotic lesions at the parental artery. Single subcortical infarctions associated with parental artery disease or those bordering on the main vessel more often have atherosclerotic characteristics than do those associated with lipohyalinosis of the penetrating artery. In countries where intracranial atherosclerosis is common, such atherosclerotic single subcortical infarctions are predicted to be prevalent. These cases, however, could not be appropriately classified in previous systems. Further effort should be devoted to formulate ischemic stroke classification systems that adequately incorporate results of recent studies and reflect the underling pathologic mechanisms, especially in patients with single subcortical infarction and intracranial atherosclerosis.
Correspondence: Jong S. Kim Asan Medical Center, University of Ulsan College of Medicine, 86 Asanbyeongwon-gil, Songpa-gu, Seoul 138-736, Korea

Tel: +82-2-3010-3442 Fax: $+82-2-474-4691$

E-mail: jongskim@amc.seoul.kr

Received: November 22, 2013

Revised: December 13, 2013

Accepted: December 14, 2013

The authors have no financial conflicts of interest.

Keywords Stroke classification; Asia; Intracranial atherosclerosis

\section{Introduction}

The etiologies of ischemic stroke are diverse, making it difficult to include all stroke subtypes within a single classification system. ${ }^{1}$ Recent advances in neuroimaging have significantly improved our understanding of the mechanisms of ischemic stroke, allowing treatment strategies to be individualized in accord with the particular stroke pathophysiology. ${ }^{2}$ Appropriate classification of ischemic stroke subtypes, based upon causative mechanism, therefore is critical for guiding treatment decisions and determining the prognosis of individual patients. Additionally, reliable and reproducible assignments to ischemic stroke subtypes are crucial for proper assessment of treatment effects in clinical trials.

Most of the previous classification systems were developed in Western countries and based on Caucasian patients, whose strokes predominantly are caused by cardiac embolism or by extracranial atherosclerosis (ECAS). These classification systems 
may not be applicable to other populations, such as Asians, in which stroke etiologies occur in different proportions. In this review, we first describe the characteristics of stroke in Asian populations and review previous classification systems. We then discuss the underlying problems in applying those classification systems to Asian patients, describe several classification systems proposed by Asian investigators, and propose some directions to resolve this important issue.

\section{Characteristics of ischemic stroke in Asians}

The proportions of stroke subtypes are well-known to differ based on race ${ }^{3}$ or ethnicity. ${ }^{4}$ According to stroke databases from Western countries, cardioembolism is the most common cause of ischemic stroke in those populations (Figure 1). ${ }^{5,6}$ In addition, sub-analysis of an American community-conducted prospective cohort study revealed that the frequency of ECAS is significantly higher in the examined groups than is that of intracranial atherosclerosis (ICAS). ${ }^{3}$

In contrast, the proportion of ICAS is higher in Asians. A study performed in Hawaii demonstrated that ECAS was more frequent in whites, whereas ICAS was noticeably more frequent in the Hawaiian-born Asian population. Korean stroke registry data showed a higher prevalence of ICAS (47.5\%) than of ECAS (19.7\%). ${ }^{7}$ Other studies performed in Asian stroke populations have demonstrated similar results. ${ }^{8,9}$ Older age, male gender, and hyperlipidemia appear to be factors favoring ECAS, where-

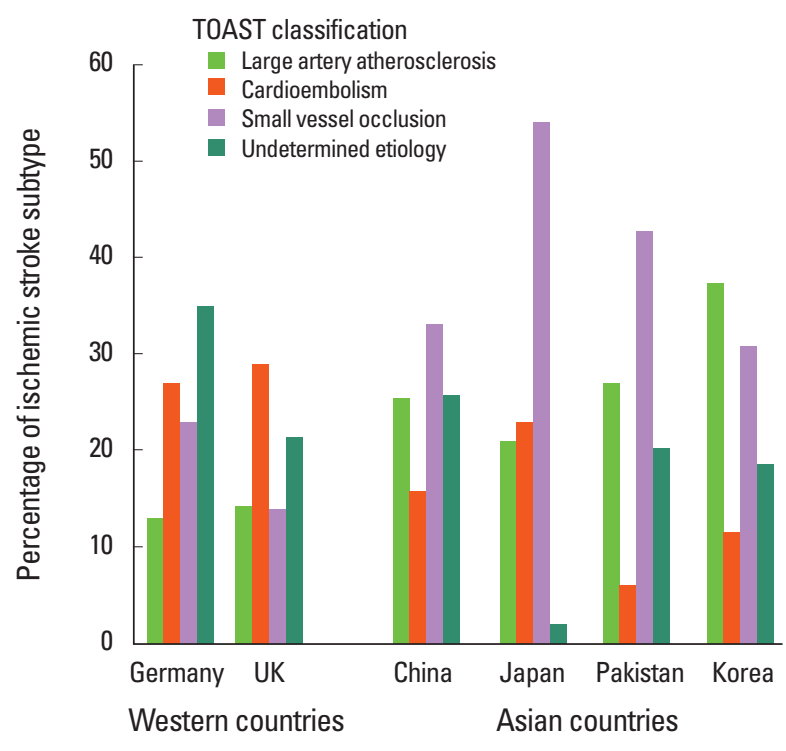

Figure 1. Comparison of ischemic stroke subtypes in Western and Asian countries. Data from Germany (ESPro), ${ }^{5}$ UK (SLESS), ${ }^{6}$ China, ${ }_{1}^{19}$ Japan (Takashima Stroke Registry), ${ }^{20}$ Pakistan (Aga Khan University Stroke Database), ${ }_{1}^{21}$ and Korea (Korean Stroke Registry) as metabolic syndrome is more closely associated with ICAS. The different prevalence of certain risk factors, such as hyperlipidemia, may contribute to the different locations of cerebral atherosclerosis. ${ }^{10}$ Another possibility is that intracranial arterial stenosis, which often is categorized as ICAS, is actually caused in Asian populations by non-atherosclerotic conditions such as moyamoya disease or intracranial dissection. ${ }^{11}$ The definitive reasons why ICAS is more prevalent in Asians remain uncertain.

ECAS predominantly causes stroke by artery-to-artery embolism. The pathologic and imaging markers of vulnerable carotid plaque have been well-investigated. ${ }^{12}$ The mechanisms by which ICAS causes stroke, however, are much diverse: 1) artery-to-artery embolism; 2) impaired clearance of emboli; 3) local branch occlusion; 4) in-situ thrombosis; or 5) combinations of these mechanisms. ${ }^{13}$ In particular, branch or perforator occlusion is unique to ICAS patients. ${ }^{14}$ Branch occlusion is usually associated with milder atherosclerosis than are other mechanisms, such as artery-to-artery embolism or hemodynamic instability. Even in patients with no apparent stenosis on neuroimaging studies, a small plaque on the vessel wall can still cause a single subcortical infarction (SSI). ${ }^{15,16}$ Limitations have been noted in the ability of conventional vascular imaging techniques to confirm mild vascular lesions associated with early atherosclerosis. ${ }^{17}$

Small-vessel occlusion is another major ischemic stroke subtype more common in Asian than in Western populations. ${ }^{18} \mathrm{~A}$ meta-analysis comparing Chinese and Caucasian stroke patients demonstrated a higher prevalence of small-vessel occlusion (33.1\% vs. $19.3 \%$ ) in Chinese patients. The Chinese groups also were more likely to have large-artery atherosclerosis ( $25.4 \%$ vs. $14.7 \%)$, but had a lower prevalence of cardioembolic stroke (15.8\% vs. 25.7\%). ${ }^{19}$ Similar results were obtained from database studies in other Asian countries, such as the Takashima stroke registry (Japan) ${ }^{20}$ and Aga Khan University stroke databank (Pakistan). ${ }^{21}$ In the Korean stroke registry, large-artery atherosclerosis was the most frequent ischemic stroke subtype, followed by smallvessel occlusion (30.7\%); the prevalence of cardioembolism was low (11.6\%; Figure 1).?

Relatively high sodium intake and high prevalence of uncontrolled hypertension may at least in part explain the predominance of small-vessel occlusion in Asians..$^{22}$ Of note, during the last decade the relative prevalence of ischemic stroke subtypes changed: cardioembolism increased, and small-vessel occlusion decreased. These changes were observed in Korea, ${ }^{23}$ as well as in other Asian countries. ${ }^{24}$ This phenomenon may in part be related to improved blood pressure control in the region. ${ }^{24}$

The prevalence of small-vessel occlusion in Asia may be artifactually elevated due to misclassification of stroke subtypes. Small-artery disease, also referred to as "lacunar infarction," usu- 
Table 1. Stroke classification systems from Western countries

\begin{tabular}{|c|c|c|c|c|}
\hline & TOAST & SSS-TOAST & $\operatorname{CCS}$ & ASCOD \\
\hline Subtypes & $\begin{array}{l}\text { LAA } \\
\text { CE } \\
\text { SVO } \\
\text { OD } \\
\text { UD }\end{array}$ & $\begin{array}{l}\text { LAA } \\
\text { CE } \\
\text { SVO } \\
\text { OD } \\
\text { UD }\end{array}$ & $\begin{array}{l}\text { Supra-aortic LAA } \\
\text { CE } \\
\text { SVO } \\
\text { OD } \\
\text { UD }\end{array}$ & $\begin{array}{l}\text { Atherosclerosis } \\
\text { CE } \\
\text { Small-vessel disease } \\
\text { Dissection } \\
\text { Other }\end{array}$ \\
\hline $\begin{array}{l}\text { Significant stenosis degree } \\
\text { for diagnosing LAA }\end{array}$ & $>50 \%$ & $>50 \%$ (evident) & $\begin{array}{l}>50 \% \\
\text { Stenosis with plaque ulceration or } \\
\text { thrombus } \\
<50 \% \text { at the site of penetrating artery }\end{array}$ & $\begin{array}{l}>50 \% \\
<50 \% \text { with endoluminal thrombus } \\
\text { Mobile thrombus at aortic arch }\end{array}$ \\
\hline Aortic atherosclerosis & Not described & Not described & Cardioembolism & Atherosclerosis \\
\hline Diameter limitation for SVO & $15 \mathrm{~mm}$ & $20 \mathrm{~mm}$ & $20 \mathrm{~mm}$ & $15 \mathrm{~mm}$ \\
\hline Other advantages & $\begin{array}{l}\text { Simple } \\
\text { Convenient } \\
\text { Accurately predicts prognosis }\end{array}$ & $\begin{array}{l}\text { Logicals } \\
\text { Reduced prevalence of strokes } \\
\text { of undetermined etiology }\end{array}$ & $\begin{array}{l}\text { Web-based } \\
\text { Evidence-based } \\
\text { Convenient if equipment available }\end{array}$ & Integration of non-causative factors \\
\hline Other Disadvantages & $\begin{array}{l}\text { High prevalence of strokes of } \\
\text { undetermined etiology } \\
\text { Low validity and reliability in } \\
\text { specific subtypes }\end{array}$ & Complex algorithm & $\begin{array}{l}\text { Depends on modern diagnostic tools } \\
\text { Needs equipment to connect to } \\
\text { web site }\end{array}$ & $\begin{array}{l}\text { Difficulty in interpretation } \\
\text { Too many subtypes }\end{array}$ \\
\hline
\end{tabular}

LAA, large artery atherosclerosis; CE, cardioembolism; SVO, small-vessel occlusion; OD, other determined; UD, undetermined.

ally presents as SSI. SSI, however, is not always caused by "lypohyalinotic" small artery disease. Recent studies have shown that SSI or brainstem infarcts frequently are caused by 1) branch occlusion associated with parental artery atherosclerotic plaque, or by 2) arteriosclerotic proximal small-vessel disease. ${ }^{17}$ Considering the high prevalence of ICAS in Asia, a large portion of SSIs is likely to be caused by parental artery atherosclerotic disease. ${ }^{25}$ The prevalence of SSI associated with ICAS, as detected by MR angiography (MRA), was $16.9 \%-35 \%$ in Asia. ${ }^{26,27}$ The orifices of perforating arteries can be obstructed even if the degree of parental artery stenosis is less than $50 \% .{ }^{17}$ In addition, small atherosclerotic plaque, undetectable by conventional MRA, has been observed on high-resolution magnetic resonance image (HR-MRI) studies. ${ }^{28}$ Therefore, the proportion of SSIs caused by parental artery atherosclerosis may be much higher than previously suspected.

These new insights into how ICAS and small-vessel occlusion can cause stroke, of course, are not taken into account by the previous classification systems (see below) (Table 1).

\section{Previous classifications}

Before the era of the TOAST (Trials of Org 10172 in Acute Stroke Treatment) classification system, several classifications were used, based mainly on clinical presentation. The Harvard Cooperative Stroke Registry, the first published database on any medical condition, classified patients by clinical findings. Only $45 \%$ of patients received conventional angiography, and $3 \%$ underwent computerized tomography (CT) ${ }^{29}$ Nevertheless, the findings were comparable to previous registry studies based on postmortem data. ${ }^{30}$ Ten years later, the National Institute of Neurological and Communicative Disorders and Stroke (NINCDS) initiated the Stroke Data Bank, and prospectively classified stroke subtypes. ${ }^{31}$ Although $97 \%$ of the included patients underwent at least one CT scan during hospitalization, nearly half of ischemic strokes were categorized as stroke of unknown cause. The Oxfordshire Community Stroke Project also utilized a classification system based on clinical findings. Due to the simplicity of the system, the inter-observer reliability was moderate $(\mathrm{k}=0.54) .^{32}$ This classification was based mainly on neurological symptoms, and the poor reliability in certain neurological signs such as hemianopia $(\mathrm{k}=0.39)$ and sensory loss $(\mathrm{k}=0.15)$ influenced the overall reliability. The scheme addressed the severity and outcome of stroke, but not the causes, and did not accurately discriminate between lacunar and small-volume cortical infarctions. ${ }^{33}$

\section{TOAST classification}

TOAST classification was the first classification system based on stroke mechanisms, and currently is the most widely used. Vascular risk factors, ${ }^{34}$ early recurrence ${ }^{35}$ and even long-term recurrence and survival ${ }^{5}$ were found to be different according to ischemic stroke subtypes classified by TOAST. Although the TOAST system was straightforward and valid, it had several important limitations. First, the inter-rater reliability was only moderate. ${ }^{36}$ The reliability for small-vessel occlusions was lower than for other ischemic stroke subtypes (see below). This discrepancy may have been related to the criteria limiting smallvessel occlusions to subcortical lesions smaller than $15 \mathrm{~mm}$. Second, only ischemic strokes with stenosis $>50 \%$ in the corre- 
sponding artery were classified as large-artery atherosclerosis; mild stenosis $(<50 \%)$ with a potential to generate distal embolization, was ignored. SSIs larger than $15 \mathrm{~mm}$, and embolic infarctions with vulnerable plaque with stenosis $<50 \%$, were classified as stroke of undetermined etiology. Approximately $40 \%$ of ischemic strokes thus remained in the undetermined category. Newer classification systems therefore were considered to resolve these problems.

\section{Modifications of the TOAST classification}

The first new classification scheme proposed was Stop-Stroke Study TOAST (SSS-TOAST). ${ }^{37}$ Each causative category was subdivided according to the level of evidence, and algorithms were used to determine the most likely etiology. The criteria for small-vessel occlusion were widened from "less than $15 \mathrm{~mm}$ " to "20 mm." Even if a SSI was larger than $20 \mathrm{~mm}$, it could be classified as a small-vessel occlusion according to the algorithm if there was no "evident" support for classification into other categories. Additionally, embolic infarctions with corresponding stenosis less than 50\%, with plaque protruding into the vessel lumen, could be classified as large-artery atherosclerosis, in the absence of evidence suggesting other categories. These algorithms decreased the percentage of strokes designated "of undetermined etiology" to $4 \%$. The more complicated scheme, however, impeded wide use of this method. Therefore, the complex algorithms of SSS-TOAST were automated in the next classification system, The Causative Classification System (CCS), which was a web-based. If multiple potential causes were present, the patient automatically was assigned to the most likely mechanism. The decision was based on the following sources of data: 1) clinical evaluation; 2) neuroimaging (CT or MRI); 3) extraand intracranial vascular investigations (carotid doppler/transcranial doppler, MRA, CT angiography, or conventional angiography); 4) cardiac evaluation (electrocardiogram, echocardiography, and Holter monitoring); and 5) other workup for uncommon causes of stroke. The criteria for small-vessel occlusion were identical to those of SSS-TOAST $(<20 \mathrm{~mm})$. This new process, yielded a high inter-rater reliability, without inflating the unclassified category. ${ }^{38}$ The system, however, depended on the availability of modern diagnostic technology. Another issue was that strokes caused by aortic arch atherosclerosis were categorized as cardioembolic. ${ }^{39}$

\section{Phenotypic classification}

The first purely phenotypic classification system was the AS$\mathrm{CO}$ system. ${ }^{40}$ Every patient is characterized by A-S-C-O: atherosclerosis, small-vessel disease, cardiac source, and other causes. This system therefore includes all the potential pheno- types of a given patient. According to the level of evidence, each of the 4 ASCO phenotypes is graded 1, 2, or 3; 1 for "definitely a potential cause of the index stroke," 2 for "causality uncertain," or 3 for "unlikely a direct cause of the index stroke (but disease is present)." When the disease is completely absent, the grade is 0 ; when grading is not possible due to insufficient workup, the grade is 9 . For example, a patient with $70 \%$ ipsilateral symptomatic stenosis, leukoaraiosis, atrial fibrillation, and platelet count of 700,000/ $\mathrm{mm}$ would be classified as A1-S3-C1-O3. Thus, the ASCO system assigns a level of likelihood to each potential cause and chooses the most likely etiology, but without ignoring other unrelated vascular conditions. The system may be utilized flexibly according to the treating physicians. A patient's treatment can be adapted to the observed phenotypes and the most likely etiology (e.g., that designated grade 1 in one of the 4 ASCO phenotypes), while clinical trials may focus on several of these 4 phenotypes (e.g., patients designated A1-A2).

Comparing cases categorized with ASCO grade 1 (ASCO-1) to those categorized by the TOAST classification system, the proportion of strokes attributed to small-vessel occlusion decreased, and those attributed to larger-artery atherosclerosis increased, in ASCO-1. These differences may be due to the different criteria of the two systems: although the diameter criteria of ASCO are identical to those of TOAST ( $<15 \mathrm{~mm}$ ), ASCO-1 includes in the small-vessel disease subgroup only deep-branch artery strokes with an additional old or silent infarct documented by MRI or CT. The atherothrombosis subgroup allows inclusion of any atherosclerotic stenosis less than $70 \%$ with attached luminal thrombosis. The inter-rater reliability was good to excellent. ${ }^{41}$ The ASCO system has merit in that no information is neglected, but the many possible combinations can readily generate confusion. Moreover, the subtypes strongly depend on the completeness of diagnostic workup.

Recently, ASCO phenotyping was upgraded to ASCO-D by adding " $D$ " for dissection. ${ }^{42}$ The degree of stenosis for determining the causality of atherothrombosis was lowered: A1 (potentially causal for index stroke), which was defined in ASCO as atherosclerotic stenosis of $70 \%-90 \%$ in an intra- or extracranial artery, was changed to ipsilateral atherosclerotic stenosis between 50\%-99\%. A2 (causal link uncertain), which was defined in ASCO as 70\%-90\% stenosis with weak evidence, was changed to ipsilateral atherosclerotic stenosis between 30\%-50\%. ${ }^{42}$

\section{Qualifications for good classification systems}

One of the key qualities of a good classification system is high reliability, including inter-observer and intra-observer agree- 
ment. The result of subtyping must be repeated faithfully by a different observer and by the same observer. Reliability usually is measured by kappa values $(\mathrm{k})$. In previous studies, the interobserver agreement on ischemic stroke subtypes classified by the TOAST system was moderate $(0.4<\mathrm{k}<0.6){ }^{43}$ The computer-based algorithm increased the inter-observer agreement significantly $(0.8<\mathrm{k}<1) .{ }^{44} \mathrm{~A}$ retrospective medical and imaging review, however, showed that the inter-observer reliability differed depending on the stroke subtype: the reliability was high for strokes due to large-artery atherosclerosis $(\mathrm{k}=0.80)$ or cardioembolism $(\mathrm{k}=0.80)$, but was low for strokes caused by small-vessel occlusion $(\mathrm{k}=0.53) .{ }^{45}$ Considering the low reliability for unknown causes $(k=0.40)$, there may have been a relatively high discrepancy in classifying ischemic stroke into the categories of small-vessel occlusion or undetermined etiology. The TOAST classification system limits small-vessel occlusion to a lesion smaller than $15 \mathrm{~mm}$ in diameter, and larger lesions are classified as of undetermined etiology if they do not fit into any other categories. These restrictions may be the main causes of the low inter-observer reliability for small-vessel occlusion.

A good classification system also should prove its validity. Validity is not guaranteed by a high reliability. Validity is usually compared to a gold standard, and presented as sensitivity, specificity, and positive predictive value. The gold standard for stroke subtyping, however, is debatable. Using as the gold standard the final diagnosis at 3 months after stroke, the validity varied according to stroke subtypes. ${ }^{45}$ The sensitivity was high and the specificity was low for strokes due to small-vessel occlusion, whereas the sensitivity was low and the specificity was high for strokes of undetermined causes. This result suggests that although a stroke is initially categorized as due to small-vessel occlusion based on the lesion diameter and location, evaluations during the following 3 months may reveal another cause of infarction. The validity of ischemic stroke subtyping was also compared among existing classifications. ${ }^{41}$ Agreement between TOAST and ASCO1 was high for cardioembolism/cardio-aortic infarction and for large-artery atherosclerosis/atherothrombosis associated with strokes. The agreement for strokes due to small-vessel occlusion and strokes of undetermined causes were relatively low, likely related to the category being changed by the lesion diameter criteria.

Convenience should also be considered in establishing a good classification system. Although the TOAST system has various limitations, it is still the most widely-used classification, probably due to its convenience. Various modified TOAST classifications have partially resolved problems of the original TOAST system, but the complex algorithm and the web-based requirement still prevents more extensive use of those methods.
Finally, ischemic stroke subtyping ideally should incorporate updated scientific knowledge, and should be based on research evidence. The TOAST classification was based on neurological signs, brain imaging findings, and ancillary diagnostic tests. However, no methodological obligations for vessel investigation were required. Since then, techniques such MRA and HR-MRI have been developed. The accuracy with which the stroke mechanism could be diagnosed thereby improved, and the traditional concepts of stroke mechanism evolved. Such progress should be included in an updated ischemic stroke classification system.

\section{Classification issues considering stroke in Asia}

As discussed above, small-vessel occlusion and ICAS are the two most common subtypes of ischemic stroke in Asian countries. Understanding of the mechanisms of ICAS and SSI has recently increased enormously. The new information, however, does not fit traditional classification systems such as TOAST.

In most of the previous criteria developed in Western nations, lesion diameter for the small-vessel occlusion subgroup was limited ( $<15$ or $20 \mathrm{~mm}$ ). This limitation was developed to distinguish infarcts due to small-vessel occlusion from embolic infarcts secondary to embolism from a diseased heart or ECAS. ${ }^{46,47}$ A recent study, however, demonstrated that strictly subcortical infarctions are rarely caused by embolism. ${ }^{48}$ Branching of a common perforator or a diffuse small plaque on the vessel wall obstructing orifices of multiple perforators is a more plausible explanation for large subcortical infarctions, at least in Asian patients. Considering these mechanisms, lesion number (single vs. multiple), not lesion size (large vs. small), may more accurately reflect the pathophysiology. The term SSI may be more appropriately defined as "single subcortical infarction" than as "small subcortical infarction."

As mentioned above, the mechanisms of SSI are diverse. Clearly, many SSIs are due to small-artery disease (lipohyalinotic perforator disease) and clinically present as a classic lacunar syndrome (pure motor stroke, pure sensory stroke, sensory-motor stroke, dysarthria-clumsy hand, and ataxic hemiparesis). However, SSI caused by parental artery atherosclerotic disease is more closely associated with indicators of atherosclerosis (previous history of coronary heart disease, atherosclerosis in other cerebral arteries), than those without parental disease. ${ }^{49}$ Therefore, it is not advisable to categorize these groups together. It would be more reasonable to consider SSI associated with parental artery disease as large-artery disease, regardless of the lesion size.

Moreover, the TOAST classification system defined large-artery atherosclerosis as when stenosis in the corresponding ar- 
tery is $>50 \% .{ }^{50}$ In SSS-TOAST, mild stenosis was regarded as a source of stroke, but only when 2 or more transient ischemic events were confirmed. ${ }^{37}$ ASCO also did not sufficiently consider SSI with mild parental arterial disease. Therefore, SSIs with mild $(<50 \%)$ parental artery disease, and SSIs which are larger than 15 or $20 \mathrm{~mm}$ are mistakenly classified as small-vessel disease and cryptogenic stroke, respectively. Actually, recent studies using MRA or HR-MRI have shown that vessels with milder stenosis or even with no stenosis on MRA (but with plaques apparent on HR-MRI) can produce SSIs by way of branch occlusion, and that they are clearly associated with atherosclerotic characteristics. Therefore, they should be classified as large-artery atherosclerosis.

Finally, SSI extending to the surface of the parental artery (proximal SSI) demonstrated a larger initial volume ${ }^{28}$ and a higher prevalence of associated parental artery disease. Even in proximal SSI without parental artery disease, asymptomatic cerebral atherosclerosis was more prevalent than in SSI located in the more distal region. ${ }^{49}$ Plaques, especially those located in the superior wall of the vessel adjacent to the perforator, are often identifiable by HR-MRI, even if conventional MRA findings are normal. ${ }^{51}$ Because of vascular remodeling, the arterial lumen evaluated by MRA may appear normal even though significant atherosclerosis plaque exists. ${ }^{28,52}$ Appropriate classifications should therefore be established for patients demonstrating indicators of atherosclerosis, despite normal MRA findings.

ICAS can cause artery-to-artery embolism in addition to branch occlusion..$^{53}$ In contrast to the considerable data identifying plaques vulnerable for embolism in the extracranial arteries, the criteria for vulnerable plaques in intracranial arteries are scanty.
As the baseline diameter of ICAS is smaller than ECAS, even small changes in the diameter of ICAS may alter the hemodynamics sufficiently to cause plaque instability or rupture. ${ }^{54} \mathrm{Ac}$ cording to a recent trial, approximately one-third of symptomatic ICAS cases are caused by ICAS less than $50 \%{ }^{25}$ The TOAST classification system categorizes these cases as cryptogenic stroke. As mentioned above, SSS-TOAST requires 2 or more transient events of ischemia for a case to be diagnosed as due to possible large-artery atherosclerosis. This attempt cannot be of particular help in classifying these cases.

\section{Classification system from Asian countries}

A few classifications for stroke subtyping were suggested by Asian investigators, taking into account the previously-discussed issues (Table 2). First, subtyping ischemic stroke based on vascular imaging was addressed. ${ }^{55}$ Mild ( < 50\%) ICAS, confirmed mostly by MRA, was considered as significant arterial disease if the stenosis was located at the site of the index stroke. In this system, patients with subcortical infarction with even mild ICAS were categorized as having large-artery atherosclerosis, rather than small-vessel occlusion. The limitation of maximum diameter of the lesion for categorization as a small-vessel occlusion was the same as that used for the TOAST classification. As a result, the proportion of cases of large-artery atherosclerosis increased compared to those classified using the TOAST criteria.

Meanwhile, another Korean group proposed a new subtype classification, based on treatment and etiologic mechanism. ${ }^{56}$

Table 2. Stroke classification systems from Asian countries

\begin{tabular}{|c|c|c|c|}
\hline & Kim et al. $(2005)^{49}$ & Han et al. $(2007)^{50}$ & $\operatorname{CISS}(2011)^{51}$ \\
\hline Subtypes & $\begin{array}{l}\text { LAA } \\
\text { CE } \\
\text { SVO occlusion } \\
\text { OD } \\
\text { UD }\end{array}$ & $\begin{array}{l}\text { Atherothrombosis } \\
\text { CE } \\
\text { Small artery disease } \\
\text { OD } \\
\text { UD }\end{array}$ & $\begin{array}{l}\text { LAA } \\
\text { Cardiogenic stroke } \\
\text { Penetrating artery disease } \\
\text { OD } \\
\text { UD }\end{array}$ \\
\hline $\begin{array}{l}\text { Significant stenosis for } \\
\text { diagnosing LAA }\end{array}$ & $\begin{array}{l}\text { Stenosis considered to be responsible for stroke } \\
\text { Degree not limited }\end{array}$ & $\begin{array}{l}>50 \% \\
\text { Any degree of stenosis with single } \\
\text { ischemic lesion on perforating artery }\end{array}$ & $\begin{array}{l}>50 \% \text { or unstable plaque } \\
\text { Penetrating artery territory infarction with } \\
\text { atherosclerotic plaque on HR-MRI or any } \\
\text { degree of stenosis }\end{array}$ \\
\hline Aortic arch atherosclerosis & Not described & Atherosclerosis & LAA \\
\hline Diameter limitation for SVO & $20 \mathrm{~mm}$ & No limitation & No limitation \\
\hline Other advantages & $\begin{array}{l}\text { Only simple changes to the widely-used TOAST } \\
\text { classification }\end{array}$ & $\begin{array}{l}\text { Considered underlying atherosclerosis } \\
\text { burden Reduced proportion of strokes } \\
\text { of undetermined etiology }\end{array}$ & $\begin{array}{l}\text { Classified single subcortical infarctions } \\
\text { according to mechanism }\end{array}$ \\
\hline Other disadvantages & $\begin{array}{l}\text { Still limits diameter for small-vessel occlusion } \\
\text { Subjective definition of stenosis responsible for } \\
\text { LAA }\end{array}$ & $\begin{array}{l}\text { Totally different from previous } \\
\text { classification systems }\end{array}$ & $\begin{array}{l}\text { Unclear description of "unstable plaque" } \\
\text { Depends on advanced imaging techniques }\end{array}$ \\
\hline
\end{tabular}

LAA, large artery atherosclerosis; CE, cardioembolism; SVO, small-vessel occlusion; OD, other determined; UD, undetermined. 
This classification system also defined atherothrombosis without criteria limiting the degree of stenosis, but one or more pieces of evidence of systemic atherosclerosis was needed to classify the stroke as due to atherothrombosis. However, in the absence of indications of systemic atherosclerosis, such patients would be classified as having had stroke of undetermined etiology. Small-artery disease was defined as causing a single ischemic lesion in the territory of a single perforator artery, in the context of normal angiography findings. A strict lesion size criterion was not given. This new classification increased the proportion of strokes attributed to atherothrombosis/large artery atherosclerosis, and decreased the proportion attributed to smallvessel occlusion.

Recently, Chinese investigators suggested a new classification system, the Chinese ischemic stroke classification (CISS). ${ }^{57} \mathrm{In}$ this system, ischemic strokes in a penetrating artery territory are classified as due to large-artery atherosclerosis when any degree of parental artery stenosis is present. Cases could even be included as large-artery atherosclerosis when arterial plaque was demonstrated by HR-MRI, even if no significant stenosis is present on MRA. Any degree of vulnerable plaque in the major arteries (aorta, extra- and intracranial) was also considered as an embolic source, and patients with such findings were classified as having large-artery atherosclerosis. However, the exact criteria for vulnerable plaque were not described, and as a result, inter-rater differences are likely to increase. Penetrating artery disease was defined as causing an acute isolated infarct in a clinically-relevant territory of one penetrating artery, regardless of the infarct size.

The classification systems suggested by Asian investigators share similar concerns in the definition of ischemic stroke subtypes: 1) lesion size limitations should not be strictly applied for small-vessel occlusion; and 2) the degree of stenosis of atherosclerotic vessels should not be limiting in determining largeartery disease subtypes.

\section{Future directions}

Neuroimaging technologies and understanding of stroke me- chanisms have significantly improved since the TOAST classification was first introduced. Updating the widely-used TOAST classification, but without losing its simplicity, has become our challenge in the development of an improved classification system (Table 3).

The prevalence of small-vessel occlusion and ICAS is high in Asian countries. These two conditions have similar features, and these aspects recently have been actively investigated by Asian physicians. These efforts have illustrated that previous classification systems are insufficient.

Considering that SSI with parental-artery disease is associated with atherosclerosis characteristics, classification of this condition as large-artery atherosclerosis seems reasonable. Cases with plaque identified by HR-MRI may also have to be classified as large-artery disease even if conventional MRA findings are normal. These issues are considered in the stroke classification developed in Asia, such as CISS. However, HR-MRI is still too costly to be routinely used in clinical practice. Moreover, the clinical characteristics and prognosis of patients with plaques identified by HR-MRI have not yet been characterized. Therefore, more studies are necessary to indentify real differences in SSIs with small-artery occlusion, ICAS, and plaques identified on HR-MRI. Development of inexpensive yet sensitive imaging technologies for plaque identification is needed. In addition, studies have shown that proximal SSIs have atherogenic characteristics even if they are not associated with parental artery disease. They may not be classified as large-artery disease, however, because there is no apparent large-artery pathology. However, such strokes may have to be classified as due to large-artery disease, if the intent of the classification is to characterize the pathologic nature of disease (e.g., for the purpose of elucidating the efficacy of antiatherogenic drugs). Future trials may have to consider this matter.

Evaluation of plaque in the carotid arteries has advanced through the examination of pathologic specimens obtained from endarterectomy, as well as the use of imaging methods such as ultrasonography and HR-MRI. In contrast, information on the characteristics of plaques in ICAS still remains limited. Microembolic signal monitoring is somewhat helpful in identifying

Table 3. Summary of recommendations and future research directions from Asian perspective

\begin{tabular}{cl}
\hline Revision of & Any degree of stenosis in an intracranial artery should be included as large-artery disease if the stenosis causes distal embolism or branch occlusion. \\
classification & SSI size criteria should not be used to differentiate large-artery disease from small-artery disease. \\
& HR-MRI-identified plaques that occlude a perforator to cause SSI may be classified as large-artery disease. \\
Future research & Identification of clinical and prognostic characteristics of SSI associated with HR-MRI-identified plaque. \\
directions & Identification of clinical and prognostic characteristics of SSI that abuts the parental artery. \\
& Technical developments to identify plaques in intracranial arteries at reasonable cost. \\
& MR or molecular imaging to characterize vulnerable intracranial atherosclerosis.
\end{tabular}

SSI, single subcortical infarction; HR-MRI, high-resolution magnetic resonance imaging 
vulnerable plaques, ${ }^{58}$ but its clinical utility remains limited due to the need for lengthy and inconvenient monitoring. Some efforts have been made to identify high risk plaque in ICAS patents; severity of stenosis or enhancement of the plaque on HRMRI also may indicate high embolic risk. ${ }^{59}$ Further studies using HR-MRI or other methods, such as molecular imaging technologies, may shed light to this complex issue. ${ }^{60}$

\section{References}

1. Muir KW. Heterogeneity of stroke pathophysiology and neuroprotective clinical trial design. Stroke 2002;33:1545-1550.

2. Kim D, Lee SH, Joon Kim B, Jung KH, Yu KH, Lee BC, et al. Secondary prevention by stroke subtype: a nationwide followup study in 46108 patients after acute ischaemic stroke. European Heart Journal 2013.

3. White H, Boden-Albala B, Wang C, Elkind MS, Rundek T, Wright $\mathrm{CB}$, et al. Ischemic stroke subtype incidence among whites, blacks, and Hispanics: the Northern Manhattan Study. Circulation 2005;111:1327-1331.

4. Sharma VK, Tsivgoulis G, Teoh HL, Ong BK, Chan BP. Stroke risk factors and outcomes among various Asian ethnic groups in Singapore. J Stroke Cerebrovasc Dis 2012;21:299-304.

5. Kolominsky-Rabas PL, Weber M, Gefeller O, Neundoerfer B, Heuschmann PU. Epidemiology of ischemic stroke subtypes according to TOAST criteria: incidence, recurrence, and longterm survival in ischemic stroke subtypes: A population-based study. Stroke 2001;32:2735-2740.

6. Stewart JA, Dundas R, Howard RS, Rudd AG, Wolfe CD. Ethnic differences in incidence of stroke: prospective study with stroke register. BMJ 1999;318:967-971.

7. Yu KH, Bae HJ, Kwon SU, Kang DW, Hong KS, Lee YS, et al. Analysis of 10,811 Cases with Acute Ischemic Stroke from Korean Stroke Registry: hospital-Based Multicenter Prospective Registration Study. J Korean Neurol Assoc 2006;24:535-543.

8. Huang YN, Gao S, Li SW, Huang Y, Li JF, Wong KS, et al. Vascular lesions in Chinese patients with transient ischemic attacks. Neurology 1997;48:524-525.

9. Wong KS, Huang YN, Gao S, Lam WW, Chan YL, Kay R. Intracranial stenosis in Chinese patients with acute stroke. $\mathrm{Neu}$ rology 1998;50:812-813.

10. Kim JS, Nah HW, Park SM, Kim SK, Cho KH, Lee J, et al. Risk factors and stroke mechanisms in atherosclerotic stroke: intracranial compared with extracranial and anterior compared with posterior circulation disease. Stroke 2012;43:3313-3318.

11. Sato S, Toyoda K, Matsuoka H, Okatsu H, Kasuya J, Takada T, et al. Isolated anterior cerebral artery territory infarction: dissection as an etiological mechanism. Cerebrovasc Dis 2010;29:
170-177.

12. Nighoghossian N, Derex L, Douek P. The vulnerable carotid artery plaque: current imaging methods and new perspectives. Stroke 2005;36:2764-2772.

13. Kim JS, Caplan LR, Wong KSL. Intracranial Atherosclerosis John Wiley \& Sons 2009.

14. Caplan LR. Intracranial branch atheromatous disease: a neglected, understudied, and underused concept. Neurology 1989;39: 1246-1250.

15. Klein IF, Lavallee PC, Schouman-Claeys E, Amarenco P. Highresolution MRI identifies basilar artery plaques in paramedian pontine infarct. Neurology 2005;64:551-552.

16. Swartz RH, Bhuta SS, Farb RI, Agid R, Willinsky RA, Terbrugge $\mathrm{KG}$, et al. Intracranial arterial wall imaging using high-resolution 3-tesla contrast-enhanced MRI. Neurology 2009;72:627634.

17. Kim JS, Yoon Y. Single subcortical infarction associated with parental arterial disease: important yet neglected sub-type of atherothrombotic stroke. Int J Stroke 2013;8:197-203.

18. Banerjee S, Biram R, Chataway J, Ames D. South Asian strokes: lessons from the St Mary's stroke database. QJM 2010;103:1721.

19. Tsai CF, Thomas B, Sudlow CL. Epidemiology of stroke and its subtypes in Chinese vs white populations: a systematic review. Neurology 2013;81:264-272.

20. Turin TC, Kita Y, Rumana N, Nakamura Y, Takashima N, Ichikawa $\mathrm{M}$, et al. Ischemic stroke subtypes in a Japanese population: Takashima Stroke Registry, 1988-2004. Stroke 2010;41: 1871-1876.

21. Syed NA, Khealani BA, Ali S, Hasan A, Akhtar N, Brohi H, et al. Ischemic stroke subtypes in Pakistan: the Aga Khan University Stroke Data Bank. J Pak Med Assoc 2003;53:584-588.

22. Singh RB, Suh I, Singh VP, Chaithiraphan S, Laothavorn P, Sy $\mathrm{RG}$, et al. Hypertension and stroke in Asia: prevalence, control and strategies in developing countries for prevention. J Hum Hypertens 2000;14:749-763.

23. Jung KH, Lee SH, Kim BJ, Yu KH, Hong KS, Lee BC, et al. Secular trends in ischemic stroke characteristics in a rapidly developed country: results from the Korean Stroke Registry Study (secular trends in Korean stroke). Circ Cardiovasc Qual Outcomes 2012;5:327-334.

24. Kubo M, Kiyohara Y, Ninomiya T, Tanizaki Y, Yonemoto K, Doi $Y$, et al. Decreasing incidence of lacunar vs other types of cerebral infarction in a Japanese population. Neurology 2006;66: 1539-1544.

25. Kwon SU, Hong KS, Kang DW, Park JM, Lee JH, Cho YJ, et al. Efficacy and safety of combination antiplatelet therapies in patients with symptomatic intracranial atherosclerotic stenosis. 
Stroke 2011;42:2883-2890.

26. Bang OY, Heo JH, Kim JY, Park JH, Huh K. Middle cerebral artery stenosis is a major clinical determinant in striatocapsular small, deep infarction. Arch Neurol 2002;59:259-263.

27. Mok VC, Fan YH, Lam WW, Hui AC, Wong KS. Small subcortical infarct and intracranial large artery disease in Chinese. J Neurol Sci 2003;216:55-59.

28. Yoon Y, Lee DH, Kang DW, Kwon SU, Kim JS. Single subcortical infarction and atherosclerotic plaques in the middle cerebral artery: high-resolution magnetic resonance imaging findings. Stroke 2013;44:2462-2467.

29. Caplan LR. Stroke classification: A personal view. Stroke 2011; 42:S3-6

30. Mohr JP, Caplan LR, Melski JW, Goldstein RJ, Duncan GW, Kistler JP, et al. The Harvard Cooperative Stroke Registry: a prospective registry. Neurology 1978;28:754-762.

31. Foulkes MA, Wolf PA, Price TR, Mohr JP, Hier DB. The Stroke Data Bank: design, methods, and baseline characteristics. Stroke 1988;19:547-554.

32. Lindley RI, Warlow CP, Wardlaw JM, Dennis MS, Slattery J, Sandercock PA. Interobserver reliability of a clinical classification of acute cerebral infarction. Stroke 1993;24:1801-1804.

33. Bamford J, Sandercock P, Dennis M, Warlow C, Jones L, McPherson K, et al. A prospective study of acute cerebrovascular disease in the community: the Oxfordshire Community Stroke Project 1981-86. 1. Methodology, demography and incident cases of first-ever stroke. J Neurol Neurosurg Psychiatry 1988; 51:1373-1380.

34. Schulz UG, Rothwell PM. Differences in vascular risk factors between etiological subtypes of ischemic stroke: importance of population-based studies. Stroke 2003;34:2050-2059.

35. Lovett JK, Coull AJ, Rothwell PM. Early risk of recurrence by subtype of ischemic stroke in population-based incidence studies. Neurology 2004;62:569-573.

36. Goldstein LB, Jones MR, Matchar DB, Edwards LJ, HoffJ, Chilukuri V, et al. Improving the reliability of stroke subgroup classification using the Trial of ORG 10172 in Acute Stroke Treatment (TOAST) criteria. Stroke 2001;32:1091-1098.

37. Ay H, Furie KL, Singhal A, Smith WS, Sorensen AG, Koroshetz WJ. An evidence-based causative classification system for acute ischemic stroke. Ann Neurol 2005;58:688-697.

38. Ay H, Benner T, Arsava EM, Furie KL, Singhal AB, Jensen MB, et al. A computerized algorithm for etiologic classification of ischemic stroke: the Causative Classification of Stroke System. Stroke 2007;38:2979-2984.

39. Saver JL. Optimizing an evidence-based causative classification system for ischemic stroke. Ann Neurol 2006;59:434; author reply 434-435.
40. Amarenco P, Bogousslavsky J, Caplan LR, Donnan GA, Hennerici MG. New approach to stroke subtyping: the A-S-C-O (phenotypic) classification of stroke. Cerebrovasc Dis 2009;27:502508.

41. Marnane M, Duggan CA, Sheehan OC, Merwick A, Hannon $\mathrm{N}$, Curtin D, et al. Stroke subtype classification to mechanismspecific and undetermined categories by TOAST, A-S-C-O, and causative classification system: direct comparison in the North Dublin population stroke study. Stroke 2010;41:15791586.

42. Amarenco P, Bogousslavsky J, Caplan LR, Donnan GA, Wolf ME, Hennerici MG. The ASCOD phenotyping of ischemic stroke (Updated ASCO Phenotyping). Cerebrovasc Dis 2013; 36:1-5.

43. D’Olhaberriague L, Litvan I, Mitsias P, Mansbach HH. A reappraisal of reliability and validity studies in stroke. Stroke 1996; 27:2331-2336.

44. Arsava EM, Ballabio E, Benner T, Cole JW, Delgado-Martinez MP, Dichgans M, et al. The Causative Classification of Stroke system: an international reliability and optimization study. Neurology 2010;75:1277-1284.

45. Meschia JF, Barrett KM, Chukwudelunzu F, Brown WM, Case LD, Kissela BM, et al. Interobserver agreement in the trial of org 10172 in acute stroke treatment classification of stroke based on retrospective medical record review. J Stroke Cerebrovasc Dis 2006;15:266-272.

46. Horowitz DR, Tuhrim S, Weinberger JM, Rudolph SH. Mechanisms in lacunar infarction. Stroke 1992;23:325-327.

47. Donnan GA, Bladin PF, Berkovic SF, Longley WA, Saling MM. The stroke syndrome of striatocapsular infarction. Brain 1991; 114 (Pt 1A):51-70.

48. Cho AH, Kang DW, Kwon SU, Kim JS. Is $15 \mathrm{~mm}$ size criterion for lacunar infarction still valid? A study on strictly subcortical middle cerebral artery territory infarction using diffusion-weighted MRI. Cerebrovasc Dis 2007;23:14-19.

49. Nah HW, Kang DW, Kwon SU, Kim JS. Diversity of single small subcortical infarctions according to infarct location and parent artery disease: analysis of indicators for small vessel disease and atherosclerosis. Stroke 2010;41:2822-2827.

50. Adams HP Jr, Bendixen BH, Kappelle LJ, Biller J, Love BB, Gordon DL, et al. Classification of subtype of acute ischemic stroke. Definitions for use in a multicenter clinical trial. TOAST. Trial of Org 10172 in Acute Stroke Treatment. Stroke 1993;24: $35-41$.

51. Chung JW, Kim BJ, Sohn CH, Yoon BW, Lee SH. Branch atheromatous plaque: a major cause of lacunar infarction (highresolution MRI study). Cerebrovasc Dis Extra 2012;2:36-44.

52. Klein IF, Lavallee PC, Touboul PJ, Schouman-Claeys E, Ama- 
renco P. In vivo middle cerebral artery plaque imaging by highresolution MRI. Neurology 2006;67:327-329.

53. Lee DK, Kim JS, Kwon SU, Yoo SH, Kang DW. Lesion patterns and stroke mechanism in atherosclerotic middle cerebral artery disease: early diffusion-weighted imaging study. Stroke 2005;36: 2583-2588.

54. Shah PK. Mechanisms of plaque vulnerability and rupture. J Am Coll Cardiol 2003;41:15S-22S.

55. Kim JT, Yoo SH, Kwon JH, Kwon SU, Kim JS. Subtyping of ischemic stroke based on vascular imaging: analysis of 1,167 acute, consecutive patients. J Clin Neurol 2006;2:225-230.

56. Han SW, Kim SH, Lee JY, Chu CK, Yang JH, Shin HY, et al. A new subtype classification of ischemic stroke based on treatment and etiologic mechanism. Eur Neurol 2007;57:96-102.

57. Gao S, Wang YJ, Xu AD, Li YS, Wang DZ. Chinese ischemic stroke subclassification. Front Neurol 2011;2:6.

58. Markus H. Transcranial Doppler detection of circulating cerebral emboli. A review. Stroke 1993;24:1246-1250.

59. Kim JM, Jung KH, Sohn CH, Moon J, Han MH, Roh JK. Middle cerebral artery plaque and prediction of the infarction pattern. Arch Neurol 2012;69:1470-1475.

60. Lee DK, Nahrendorf M, Schellingerhout D, Kim DE. Will molecular optical imaging have clinically important roles in stroke management, and how? J Clin Neurol 2010;6:10-18. 